\title{
OPTIMASI KONDISI OPERASI KOLOM DISTILASI UNTUK MENINGKATKAN KONSENTRASI ETHYLENE DICHLORIDE (EDC) UMPAN FURNACE (STUDI DI PT ASAHIMAS CHEMICAL)
}

\author{
Bintang Iwhan Moehady ${ }^{1} *$, Amanda Putri ${ }^{1}$, Esa Mayasari ${ }^{1}$ \\ ${ }^{1}$ Jurusan Teknik Kimia, Politeknik Negeri Bandung \\ Jln. Gegerkalong Hilir, Ds. Ciwaruga, Bandung 40012 \\ "E-mail: bintang@ polban.ac.id
}

\begin{abstract}
ABSTRAK
Ethylene Dichloride (EDC) dengan konsentrasi yang tinggi akan menghasilkan Vinyl Chloride Monomer (VCM) dengan konsentrasi yang tinggi. EDC akan mengalami perengkanhan menjadi VCM didalam peralatan yang disebut furnace. Konsentrasi EDC yang tinggi akan memperpanjang umur furnace karena terdapat lebih sedikit High Boiling Component (HBC) yang mengakibatkan terbentuknya coke. Konsentrasi EDC rata-rata yang ada sebesar 99,6\% (w/w). Pada penelitian ini dilakukan simulasi untuk meningkatan konsentrasi EDC di aliran atas kolom distilasi TW-303 lebih besar atau sama dengan 0,2\% (w/w) dari 99,6\% (w/w). Optimasi variabel yang dilakukan adalah laju alir refluk kolom distilasi TW-304, tekanan kolom bagian bawah TW-304 dan tekanan kolom bagian atas TW-303. Hasil optimasi menunjukkan dapat dilakukannya peningkatan konsentrasi EDC di aliran atas kolom distilasi TW-303 sebanyak $0,2 \%(\mathrm{w} / \mathrm{w})$ dengan laju alir $77063,0859 \mathrm{~kg} / \mathrm{h}$. EDC dengan konsentrasi tersebut dapat meningkatkan umur furnace sampai dengan 1,5-2 tahun.
\end{abstract}

Kata kunci: Distilasi, Ethylene Dichloride (EDC), umpan furnace

\begin{abstract}
ABTRACT
Ethylene Dichloride (EDC) with a high concentration will producing Vinyl Chloride Monomer (VCM) with a high concentration. EDC will cracked into VCM form in an equipment which is called as furnace. EDC with a high concentration will give prolong life time for furnace, caused by the lower concentration of High Boiling Component (HBC) that effected forming of coke. The average of EDC concentration in Asahimas Chemical Co. Ltd. is 99,6\% (w/w). This research doing by the simulation to increase the concentration of EDC in feed furnace flow more than or equal as $0,2 \%(\mathrm{w} / \mathrm{w})$ from $99,6 \%(\mathrm{w} / \mathrm{w})$. Variables of optimation are reflux ratio of distilation column TW-304, bottom pressure of distilation column TW-304, and top pressure of distilation column TW-303. Optimation result's showing that increasing concentration of EDC in top flow of distilation column TW-303 as $0,2 \%$ (w/w) with the flow as $77063,0859 \mathrm{~kg} / \mathrm{h}$ can increasing the life time of furnace untill 1,5-2 years.
\end{abstract}

Keywords: Distilation, Ethylene Dichloride (EDC), feed furnace

\section{PENDAHULUAN}

Departemen VCM-2 adalah plant yang memproduksi EDC sebagai bahan utama untuk membuat VCM. EDC yang diproduksi terbagi menjadi dua yaitu EDC untuk dipasarkan dan EDC untuk umpan furnace. EDC yang diproduksi saat ini dengan kemurnian rata-rata sebesar 99,6\% (w/w) merupakan bahan baku untuk menghasilkan VCM dengan cara perengkahan, selain itu dengan konsentrasi tersebut umur furnace hanya mencapai 1 sampai dengan 1,5 tahun. Dengan kenaikan sebesar $0,2 \%(\mathrm{w} / \mathrm{w})$ 
diharapkan dapat meningkatkan kualitas VCM yang dihasilkan yang secara tidak langsung akan memperpanjang umur furnace hingga mencapai 2 tahun.

Pemurnian di seksi pemurnian EDC dirancang agar EDC yang dihasilkan sebagai umpan furnace memiliki tingkat kemurnian 99,7\% (w/w), keadaan ini ditinjau dari keluaran bagian atas kolom distilasi(Tower Destillation), TW-303. Kondisi tersebut dapat tercapai dengan melakukan simulasi pada tekanan bagian atas kolom distilasi TW-303, tekanan bagian bawah kolom distilasi(Tower Destillation), TW304 dan laju alir refluk kolom distilasi TW-304.

Tujuan penelitian ini adalah menentukan kondisi operasi tekanan bagian atas kolom distilasi TW-303, tekanan bagian bawah kolom distilasi TW-304 dan laju alir refluk kolom distilasi TW-304 optimal agar konsentrasi EDC di aliran atas kolom distilasi TW-303 naik dengan rentang $0,1 \%$ sampai dengan $0,2 \%(\mathrm{w} / \mathrm{w})$.

Penelitian ini merupakan simulasi dengan menggunakan software CHEMCAD® versi 6.5.6 untuk pembuatan model dan software Polymath ${ }^{\circledR}$ versi 6.0 untuk pengolahan data.

CHEMCAD $®$ merupakan software simulasi proses kimia untuk memperluas kemampuan seorang insinyur dalam meningkatkan produktivitas. (Onie Hercuantoro, S.T. , 2014)

Polymath ${ }^{\circledR}$ merupakan software komputasi yang telah dirancang untuk penggunaan di bidang profesi. Berbagai macam Polymath ${ }^{\circledR}$ memperbolehkan pengguna untuk menggunakan teknik analisis penomoran yang efektif untuk menyelesaikan masalah secara interaktif.

\section{METODE}

Metode yang digunakan dalam penelitian yaitu metode termodinamika untuk menghitung neraca massa dengan melakukan simulasi menggunakan software CHEMCAD $^{\circledR}$. Hasil simulasi kolom distilasi dapat digunakan untuk mengetahui peluang kenaikan konsentrasi EDC di aliran bagian atas kolom distilasi TW-303.

Tabel 2.1 Variabel yang Diamati

\begin{tabular}{lll}
$\begin{array}{l}\text { Tekanan bagian } \\
\text { bawah kolom } \\
\text { distilasi TW- }\end{array}$ & $\begin{array}{l}\text { Laju alir } \\
\text { refluk kolom } \\
\text { distilasi TW- }\end{array}$ & $\begin{array}{l}\text { Tekanan bagian } \\
\text { atas kolom } \\
\text { distilasi TW- }\end{array}$ \\
\hline P-304 1 & R1 (konstan) & 303 (konstan) \\
P-304 2 & R1 & P-303 1 \\
P-304 3 & R1 & P-303 1 \\
P-303 1
\end{tabular}




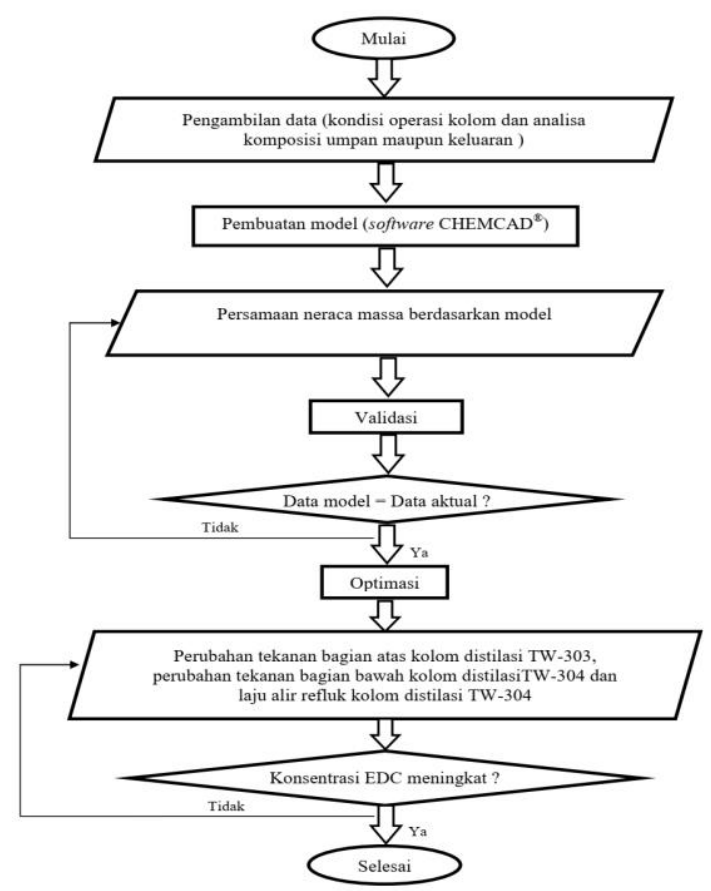

Gambar 2.1 Diagram Alir Penelitian HASIL DAN PEMBAHASAN

Pemodelan yang sudah valid kemudian dilakukan optimasi terhadap variabel kondisi operasi yang dapat mempengaruhi kinerja kolom distilasi TW-303 dan TW-304, untuk diperoleh kondisi operasi yang optimal. Kondisi optimal dinyatakan dengan peningkatan konsentrasi EDC di aliran atas kolom distilasi TW-303 hingga lebih besar atau sama dengan 0,2\% (w/w) dari nilai konsentrasi 99,6 \% (w/w). Analisis variabel yang dapat mempengaruhi konsentrasi EDC di aliran atas kolom distilasi TW-303 dilakukan dengan menggunakan software Polymath ${ }^{\circledR}$. Hasil analisa variabel yang dapat mempengaruhi kinerja kolom distilasi TW-303 dan TW-304 yaitu :

a. Tekanan bagian bawah kolom distilasi TW-304

b. Laju alir refluk kolom distilasi TW304

c. Tekanan bagian atas kolom distilasi TW-303

Data yang telah diperoleh dimasukkan ke dalam pemodelan untuk dilakukan optimasi. Berikut merupakan hasil optimasi dari masing-masing variabel kondisi operasi yang dapat mempengaruhi kinerja kolom distilasi TW-303 dan TW-304.

Tekanan bagian bawah kolom distilasi TW-304 diperkirakan dapat mempengaruhi konsentrasi EDC di aliran atas kolom distilasi TW-303. Berdasarkan perkiraan tersebut maka dilakukan simulasi perubahan tekanan bagian bawah kolom distilasi TW-304 dengan variabel kondisi operasi lain yang konstan.

Dari data yang telah diperoleh, Gambar 3.1 menunjukkan bahwa perubahan tekanan bagian bawah kolom distilasi TW-304 yang semakin tinggi (mendekati tekanan atmosfer) mengakibatkan konsentrasi EDC di aliran atas kolom distilasi TW-303 akan menurun.

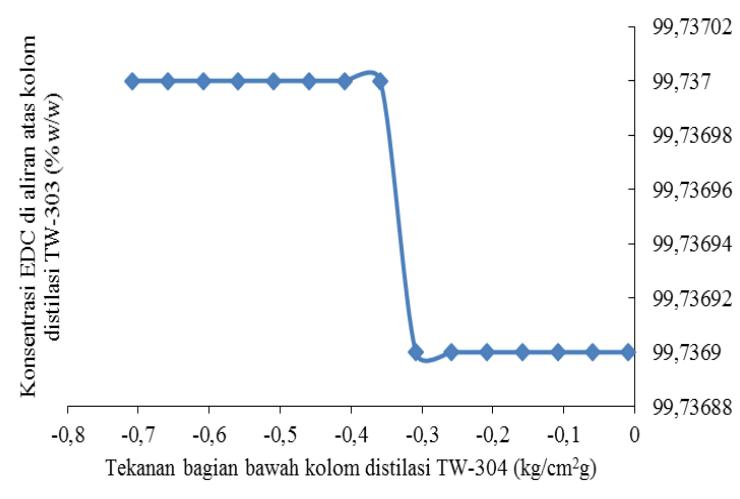

Gambar 3.1 Pengaruh tekanan bagian bawah kolom distilasi TW-304 terhadap konsentrasi EDC di aliran atas kolom distilasi TW-303

Semakin tinggi tekanan bagian bawah kolom distilasi TW-304 mengakibatkan konsentrasi $\mathrm{HBC}$ di aliran atas kolom distilasi TW-303 meningkat. Tekanan bagian bawah kolom yang semakin tinggi menyebabkan suhu kolom bagian bawah meningkat. Peningkatan suhu kolom bagian bawah dapat menyebabkan perubahan suhu titik didih terhadap komponen berat tertentu. Akibatnya jika komponen berat tertentu mengalami 
perubahan suhu titik didih dan teruapkan bersamaan dengan komponen EDC menuju kolom bagian atas, maka akan menyebabkan penurunan konsentrasi EDC di aliran atas kolom distilasi TW303 sedangkan konsentrasi HBC di aliran tersebut mengalami peningkatan.

Semakin tinggi suhu kolom bagian bawah TW-304 maka komponen HBC tertentu akan teruapkan menuju ke bagian atas kolom distilasi bersamaan dengan EDC, sehingga konsentrasi HBC di aliran bagian bawah kolom distilasi TW-304 mengalami penurunan seiring dengan semakin tingginya tekanan bagian bawah kolom distilasi TW-304 mendekati tekanan atmosfer.

Dari simulasi tersebut, diperoleh data terbaik pada kondisi operasi tekanan bagian bawah kolom distilasi TW-304 sebesar $-0,7087 \mathrm{~kg} / \mathrm{cm}^{2} \mathrm{~g}$. Hal ini dipertimbangkan berdasarkan nilai konsentrasi HBC yang paling rendah di aliran atas kolom distilasi TW-303 sebesar $0,05175 \%$ (w/w).

Simulasi pengaruh variabel kondisi operasi dilakukan terhadap variasi laju alir refluk kolom distilasi TW-304 dengan kondisi operasi lain yang konstan, untuk mengetahui pengaruh kondisi operasi dalam peningkatan konsentrasi EDC di aliran atas kolom distilasi TW-303. Variasi laju alir refluk kolom distilasi TW-304 dilakukan dengan cara pengaturan pembagian aliran (divider stream) berdasarkan rasio laju alir. Batasan nilai yang dimasukkan terhadap pembagian aliran yaitu 0,5 sampai dengan 0,54. Gambar 3.2 menunjukkan pengaruh laju alir refluk TW-304 terhadap konsentrasi EDC di aliran atas kolom distilasi TW-303.

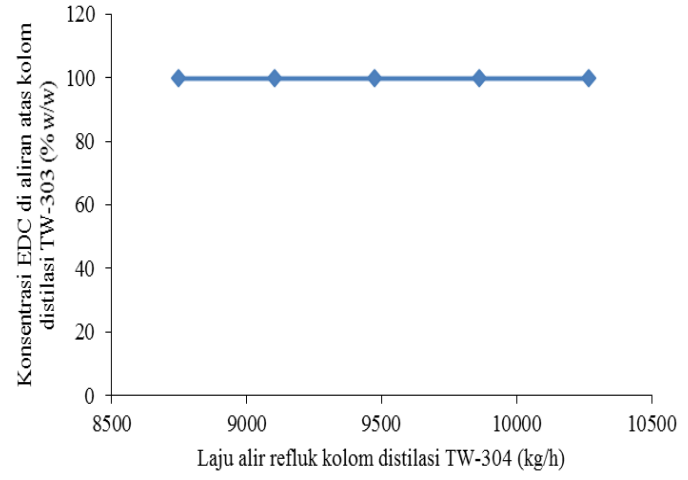

Gambar 3.2 Pengaruh laju alir refluk kolom distilasi TW-304 terhadap konsentrasi EDC di aliran atas kolom distilasi TW-303

Semakin besar laju alir refluk kolom distilasi TW-304 maka konsentrasi EDC di aliran atas kolom distilasi TW-303 semakin meningkat. Hal ini terjadi karena semakin besar laju alir ke dalam kolom distilasi dengan konsentrasi EDC yang tinggi, maka konsentrasi dari komponen EDC yang akan dipisahkan semakin besar. Namun terjadi suatu kondisi tunak atau yang biasa dikenal dengan steady state, dimana penambahan laju alir refluk ke dalam tower distilasi TW-304 tidak akan mempengaruhi kenaikan konsentrasi EDC dikarenakan keadaan yang sudah mencapai kondisi stabil. Keadaan ini berpengaruh terhadap konsentrasi HBC di aliran atas kolom distilasi TW-303. Semakin besar laju alir refluk yang dikembalikan ke kolom distilasi TW-304 menyebabkan konsentrasi HBC di aliran atas kolom distilasi TW-303 semakin menurun. Karena pada dasarnya penambahan laju alir refluk merupakan salah satu cara untuk meningkatkan konsentrasi distilat. Laju alir refluk yang memiliki konsentrasi EDC lebih tinggi dibandingkan dengan konsentrasi HBC akan meningkatkan konsentrasi EDC pada saat pemisahan di dalam kolom distilasi. Sehingga konsentrasi EDC sebagai distilat mengalami peningkatan dikarenakan pengotornya berupa 
komponen HBC mengalami penurunan konsentrasi pada aliran distilat.

Akan tetapi, penambahan laju alir refluk pada kolom distilasi TW-304 menyebabkan konsentrasi HBC di aliran produk bawah kolom distilasi TW-304 mengalami penurunan kemudian perlahan mengalami peningkatan.

Berdasarkan pertimbangan penurunan nilai konsentrasi $\mathrm{HBC}$ di aliran atas kolom 303 yang maksimal yaitu 7 ppm, didapatkan data laju alir refluk sebesar $10266,39 \mathrm{~kg} / \mathrm{h}$ atau pengaturan pada pembagian aliran dengan mode rasio laju alir sebesar 0,54.

Simulasi dilakukan juga pada tekanan bagian atas kolom distilasi TW303 agar diketahui trennya terhadap konsentrasi. Gambar 3.3 memuat informasi data dari simulasi ke-9 hingga simulasi ke-20, menunjukkan kenaikan konsentrasi EDC yang lebih jelas. Hal ini terjadi karena pada tekanan yang lebih vakum, suhu bagian bawah maupun atas kolom akan menurun sehingga HBC yang terdapat pada kolom distilasi cenderung tidak menguap menuju bagian atas kolom. HBC yang tidak teruapkan akan terkumpul dibagian bawah kolom dan dikeluarkan menjadi produk bagian bawah. Hanya uap EDC yang akan teruapkan dan menuju bagian atas kolom.

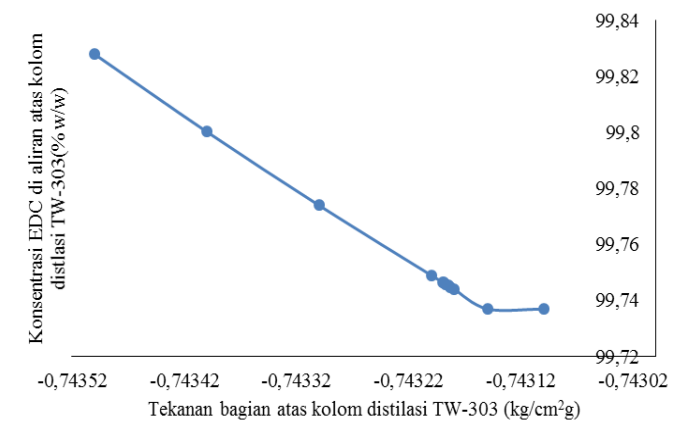

Gambar 3.3 Pengaruh tekanan bagian atas kolom distilasi TW-303 terhadap konsentrasi EDC di aliran atas kolom distilasi TW-303
Pada tekanan bagian atas kolom distilasi TW-303 sebesar $-0,74318$ $\mathrm{kg} / \mathrm{cm}^{2} \mathrm{~g}$ mulai menunjukkan terjadinya kenaikan konsentrasi EDC di aliran atas kolom distilasi TW-303, hal ini terus berlangsung dengan bertambah vakumnya tekanan bagian atas kolom distilasi TW-303 sehingga tekanan tersebut dapat digunakan sebagai acuan nilai tekanan minimal untuk mecapai kenaikan konsentrasi EDC di aliran atas kolom distilasi TW-303.

Konsentrasi EDC di aliran atas kolom distilasi TW-303 yang meningkat juga diartikan terdapat pengurangan konsentrasi pada komponen lainnya yaitu $\mathrm{HBC}$, tetapi dengan meningkatnya konsentrasi EDC di aliran atas kolom distilasi TW-303, laju alirnya pun mengalami penurunan. Pada tekanan tertentu uap di aliran atas yang keluar dari kolom distilasi TW-303 masuk ke dalam kondenser untuk melewati tahap pendinginan. Namun tidak seluruhnya uap terkondensasi, hal ini dikarenakan terjadi titik kesetimbangan uap-cair ketika pada pengaturan suhu kondenser dengan suhu uap aliran atas yang masuk ke dalam unit tersebut. Uap yang tidak terkondensasi memiliki konsentrasi EDC yang lebih tinggi dibandingkan dengan konponen yang lainnya, dan akan terbawa menuju ke aliran vent gas. Sebuah unit kompresor berfungsi sebagai pengkondisi vakum pada kolom distilasi serta membawa aliran uap yang tidak terkondensasi menuju aliran vent gas. Jika tekanan kompresor semakin vakum, maka laju alir EDC aliran atas (yang terkondensasi) akan semakin kecil.

Kondisi optimal didapatkan melalui optimasi tahap selanjutnya dengan mengkombinasikan nilai pada variabel yang mempengaruhi kosentrasi EDC di aliran atas kolom distilasi TW-303 yang telah didapatkan. Variabel yang dibuat konstan adalah laju alir refluk berdasarkan perbandingan laju alir pada kolom distilasi 
TW-304 yang digunakan adalah 0,54 karena merupakan nilai maksimal yang laju alirnya diizinkan (< 130\% dari kapasitas desain pompa) dan nilai tekanan bagian bawah kolom distilasi TW-304 sebesar -0,7087 $\mathrm{kg} / \mathrm{cm}^{2} \mathrm{~g}$. Sedangkan nilai tekanan bagian atas kolom distilasi TW-303 dibuat simulasi mulai dari $-0,74318 \mathrm{~kg} / \mathrm{cm}^{2} \mathrm{~g}$, karena pada nilai tekanan ini konsentrasi EDC di aliran atas kolom distilasi TW-304 mulai mengalami kenaikan.

Perubahan tekanan bagian atas kolom distilasi TW-303 dapat meningkatkan konsentrasi EDC di aliran atas kolom distilasi TW-303 dengan batasan nilai tekanan dari $-0,74318 \mathrm{~kg} / \mathrm{cm}^{2} \mathrm{~g}$ sampai dengan $-0,74352 \mathrm{~kg} / \mathrm{cm}^{2} \mathrm{~g}$.

Perubahan tekanan bagian atas kolom distilasi TW-303 mempengaruhi penurunan konsentrasi HBC di aliran atas kolom distilasi TW-303. Suhu bagian bawah kolom distilasi TW-304 mengalami penurunan seiring dengan penurunan tekanan bagian atas kolom distilasi. Jika terjadi hal demikian, maka HBC tidak teruapkan menuju ke bagian atas kolom distilasi melainkan terakumulasi dibagian bawah kolom distilasi. Sehingga konsentrasi HBC yang berada di aliran atas kolom distilasi TW-303 mengalami penurunan. Konsentrasi HBC di aliran bawah kolom distilasi TW304 mengalami penurunan seiring dengan semakin vakumnya tekanan bagian atas kolom distilasi TW-303.

Konsentrasi EDC di aliran atas kolom distilasi TW-303 akan terus meningkat seiring dengan menurunnya tekanan bagian atas kolom distilasi TW-303 menjadi vakum, tetapi peningkatan konsentrasi ini mengakibatkan turunnya laju alir aliran atas kolom distilasi TW-303. Laju alir aliran atas kolom distilasi TW-303 minimal yang diizinkan di lapangan adalah $70 \mathrm{~m}^{3} / \mathrm{h}$ atau sama dengan $88430 \mathrm{~kg} / \mathrm{h}$.

Pada data simulasi ke-2 dengan tekanan bagian atas kolom distilasi TW-303 sebesar $-0,7432 \mathrm{~kg} / \mathrm{cm}^{2} \mathrm{~g}$ didapatkan konsentrasi EDC di aliran atas kolom distilasi TW-303 sebesar 99,7499\% (w/w,) mempunyai laju alir sebesar 88542.5469 $\mathrm{kg} / \mathrm{h}$. Simulasi ke-2 ini memiliki konsentrasi EDC di aliran atas kolom distilasi TW-303 kurang dari 99,837\% (w/w) dengan laju alirnya sudah dalam batas minimal laju alir yang diizinkan di lapangan yaitu $88542,5469 \mathrm{~kg} / \mathrm{h}$.

Simulasi ke-9 menghasilkan konsentrasi EDC di aliran atas kolom distilasi TW-303 sebesar 99,837\% (w/w) dengan begitu konsentrasinya mencapai tujuan kenaikan 0,2\% (w/w) dari konsentrasi EDC rata-rata dilapangan, akan tetapi laju alir aliran atas kolom distilasi TW-304 yang didapatkan jauh dari batas minimal yang diizinkan di lapangan. Laju alir yang didapatkan pada simulasi ke-9 sebesar $26755,5371 \mathrm{~kg} / \mathrm{h}$.

Secara keseluruhan simulasi ke-2 memiliki persen error yang lebih kecil yaitu sebesar 0,1273\% terhadap laju alir aliran atas kolom distilasi TW-303, tetapi peningkatan konsentrasi EDC di aliran atas kolom distilasi TW-303 tidak tercapai sesuai target dari penelitian ini. Konsentrasi EDC di aliran atas kolom distilasi TW-303 yang diperoleh pada simulasi ke-2 sebesar 99,7499\% (w/w). Sedangkan pada simulasi ke-9 memiliki persen error sebesar $12,8541 \%$ terhadap laju alir aliran atas kolom distilasi TW-303, dengan konsentrasi EDC di aliran atas kolom distilasi TW-303 sebesar $99,837 \% \quad(\mathrm{w} / \mathrm{w})$ yang sudah mencapai target peningkatan konsentrasi EDC yaitu $0,2 \%(\mathrm{w} / \mathrm{w})$ dari konsentrasi EDC rata-rata dilapangam.

Upaya peningkatan kualitas EDC di aliran atas kolom distilasi TW-303 dilakukan untuk memperpanjang umur alat furnace. Umur alat furnace saat ini hanya mencapai satu tahun dengan konsentrasi EDC umpan furnace sebesar 99,6\% (w/w), hal ini disebabkan karena alirannya memiliki komponen HBC sebanyak 0,0518\% (w/w).

Konsentrasi komponen HBC yang ada di aliran atas kolom distilasi TW-303 menimbulkan coking yaitu pembentukan kerak di bagian dalam pipa yang ada pada furnace, sehingga dapat menyebabkan terjadinya pemanasan lokal dan dapat mengganggu proses perengkahan EDC menjadi VCM. Dengan pencapaian konsentrasi EDC di aliran atas kolom distilasi TW-303 sampai 99,837\% (w/w) dan mampu menurunkan konsentrasi HBC di aliran atas kolom distilasi TW-303 sampai $0,03749 \% \quad(\mathrm{w} / \mathrm{w})$ diharapkan dapat 
memperpanjang umur alat furnace. Berdasarkan data pembanding di lapangan, kemurnian EDC di aliran atas kolom distilasi TW-303 sebesar 99,7 \% (w/w) sampai dengan $99,8 \% \quad(w / w)$ dapat memperpanjang umur alat selama satu setengah sampai dengan dua tahun. Data tersebut merupakan reference competitor yang digunakan sebagai acuan dalam peningkatan kualitas EDC.

\section{SIMPULAN}

Dari hasil penelitian yang telah dilakukan dapat diperoleh kesimpulan bahwa kondisi operasi optimal agar konsentrasi EDC di aliran atas kolom distilasi TW-303 naik dengan rentang $0,1 \%$ sampai dengan $0,2 \%(\mathrm{w} / \mathrm{w})$, antara lain:

1. Konsentrasi EDC yang diperoleh sebesar 99,837\% (w/w) dengan laju alir $26755,5371 \mathrm{~kg} / \mathrm{h}$. Kondisi operasi yang digunakan adalah :

- Tekanan bagian bawah kolom distilasi TW-304 sebesar -0,7087 $\mathrm{kg} / \mathrm{cm}^{2} \mathrm{~g}$;

- Tekanan bagian atas kolom distilasi TW-303 sebesar $\quad-0,743521$ $\mathrm{kg} / \mathrm{cm}^{2} \mathrm{~g}$; dan

- Laju alir refluk berdasarkan pengaturan rasio laju alir kolom distilasi TW-304 sebesar 0,54.
2. Konsentrasi EDC yang diperoleh sebesar 99,7499\% (w/w), maka diperoleh laju alirnya sebanyak $88542,5469 \mathrm{~kg} / \mathrm{h}$. Kondisi operasi yang digunakan adalah

- Tekanan bagian bawah kolom distilasi TW-304 sebesar $-0,7087$ $\mathrm{kg} / \mathrm{cm}^{2} \mathrm{~g}$;

- Tekanan bagian atas kolom distilasi TW-303 sebesar $-0,7432 \mathrm{~kg} / \mathrm{cm}^{2} \mathrm{~g}$; dan

- Laju alir refluk berdasarkan pengaturan rasio laju alir TW-304 sebesar 0,54.

\section{DAFTAR RUJUKAN}

Mc Cabe, W. L. 1990. Operasi Teknik Kimia. Jakarta: Erlangga.

Richardson, C. A. 2005. Chemical Engineering Design. Oxford: Elsevier ButterworthHeinemann.

Tham, M. T. 2009. Distillation. New Zealand: R. C. Costello and Associaters, Inc.

Doherty, M. F.; Fidkowski, Z. T.; Malone, M. F.; \& Taylor, R. 2008. Perry's Chemical Engineers' Hand Book. United States of America : McGrawHill. 